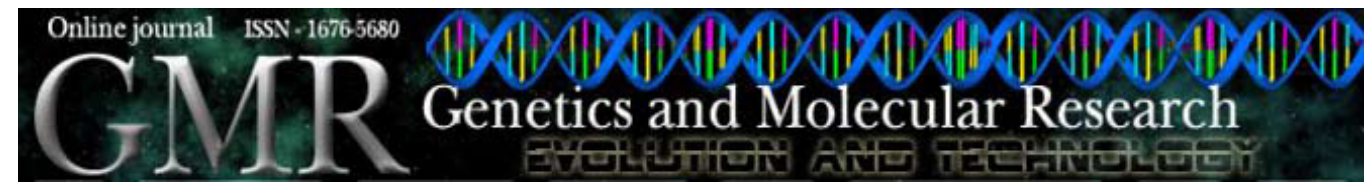

\title{
Intra- and interspecific variation of cuticular hydrocarbon composition in two Ectatomma species (Hymenoptera: Formicidae) based on Fourier transform infrared photoacoustic spectroscopy
}

\author{
W.F. Antonialli Junior, Y.R. Súarez, T. Izida, L.H.C. Andrade \\ and S.M. Lima \\ Centro Integrado de Análise e Monitoramento Ambiental, \\ Universidade Estadual de Mato Grosso do Sul (UEMS), Dourados, MS, Brasil \\ Corresponding author: W.F. Antonialli Junior \\ E-mail: williamantonialli@yahoo.com.br
}

Genet. Mol. Res. 7 (2): 559-566 (2008)

Received March 26, 2008

Accepted June 6, 2008

Published june 24, 2008

\begin{abstract}
We have been able to discriminate different castes and sexes of ants in the same colony by measuring cuticular hydrocarbon levels with Fourier transform infrared photoacoustic spectroscopy, compared by canonical discriminant function analysis. We have now applied this methodology to various colonies of two species of ants of the genus Ectatomma in the Brazilian Cerrado. There were clear interspecific differences in cuticular hydrocarbons of these ants, with a small intraspecific variation. The differences between colonies were greater in E. brunneum than in E. vizottoi. Genetic differences among the colonies and species were well estimated by Fourier transform infrared photoacoustic spectroscopy and statistical analyses.
\end{abstract}

Key words: Fourier transform infrared photoacoustic; Ectatomma; Cuticular hydrocarbon; Interspecific variation 


\section{INTRODUCTION}

Hydrocarbons are excellent markers for insects because they are permanent and abundant in the cuticle and can even be analyzed in dead individuals (Pennanec'h et al., 1995). Cuticular hydrocarbon composition has been used to identify sibling or cryptic species of Anopheles mosquitoes (Carlson and Service, 1979), sandflies (Phillips et al., 1990), Drosophila (Cobb and Jallon, 1990), beetles (Lockey, 1991; Golden et al., 1992), moths (Carlson and Milstrey, 1990; Lavine and Carlson, 1991), termites (Haverty et al., 1988; Kaib et al., 1991; Takematsu and Yamaoka, 1999) and parasitic wasps (Espelie et al., 1990). Many of these studies were motivated by the difficulty of finding morphological differences between species.

In many species of social insects, the cuticular hydrocarbons of adults vary among colonies and can also be affected by physiological processes, such as oogenesis (Blomquist et al., 1998; Lenoir et al., 1999). Dietemann et al. (2003) suggested that cuticular hydrocarbons allow recognition of queens and egg-laying workers. A recent study showed that cuticular hydrocarbon varies among the castes of different species of social insects, such as Melipona bicolor (Abdalla et al., 2003). According to Armold and Regnier (1975), the cuticular hydrocarbon profiles in honey bees are partly genetically determined, and they differ among subfamilies suggesting that they could be used by workers as "signatures" for subfamily recognition.

Various studies examining cuticular hydrocarbons in social insects (Peeters et al., 1999; Liebig et al., 2000) have used gas chromatography coupled with mass spectrometry or solid-phase micro-extraction methods (Dietemann et al., 2003). These methods are efficient and precise, but they are not easy to carry out because of difficulties in sample preparation.

Recently, we showed that Fourier transform infrared photoacoustic spectroscopy (FTIR-PAS) associated with statistical analysis can contribute to interpreting cuticular hydrocarbon content in social insects (Antonialli Jr. et al., 2007). We were able to distinguish castes and sexes in the ant Ectatomma vizottoi. The mid-infrared spectra were determined directly from the abdomens of the ants, without any special sample preparation. Sibling species in ants are often separated by differences in the morphological features specific to reproduction, i.e., queens and males, or by differences in chromosome numbers, biology or behavior (Seifert, 1991). Alternative approaches to morphological identification would be useful. Biochemical and molecular techniques can overcome the limitations of morphological methods (Raboudi et al., 2004).

We assessed the potential of FTIR-PAS, combined with canonical discriminant analysis, for distinguishing two species of ants (E. vizottoi and E. brunneum) and colonies of the same species.

\section{MATERIAL AND METHODS}

\section{Material collection}

The ants were collected from underground nests in the Universidade Estadual de Mato Grosso do Sul campus in Dourados (22 $\left.13^{\prime} 16^{\prime \prime} \mathrm{S} / 54^{\circ} 48^{\prime} 20^{\prime \prime} \mathrm{W}\right)$, Mato Grosso do Sul, Brazil. After they were anesthetized by chilling on ice, the ants were killed and the abdomens were removed and placed in a vacuum dryer for $48 \mathrm{~h}$ in order to reduce the water content, which is necessary for mid-infrared spectroscopic study. 
Ten worker abdomens were analyzed from each of the two colonies of E. brunneum and of E. vizottoi. The mid-infrared measurements were made directly on the abdomen, because of the high concentration of cuticular hydrocarbons (Cuvillier-Hot et al., 2001).

\section{Fourier transform infrared photoacoustic spectroscopy}

Mid-infrared spectroscopy was carried out with a Thermo-Nicolet Nexus 670 spectrophotometer combined with a Photoacoustic detector (MTEC-300). During the measurements, the spectrophotometer was purged with pure nitrogen gas in order to eliminate $\mathrm{CO}_{2}$ and water vapor. The photoacoustic cell was purged with helium throughout acquisition. Prior to acquisition of the abdomen spectra, carbon black was used as a reference sample. Spectra were obtained between 400 and $4000 \mathrm{~cm}^{-1}$, with $8 \mathrm{~cm}^{-1}$ resolution and 64 scans per sample.

The photoacoustic effect is caused when infrared radiation impinges on a sample surface in a sealed environment, the so-called photoacoustic cell (Rosencwaig, 1980). Due to sample absorption and consequently the nonradiative deexcitation process of the modulated infrared beam, thermal waves are created in the He gas and propagate to the sensitive microphone in the photoacoustic cell; these waves are transformed into a spectrum by A/D conversion. When absorption is high, the thermal wave has a high amplitude and the vibration of the microphone is increased. For more details on this method, see Letzelter et al. (1995) and Belton et al. (1988).

Because abdomens of workers have different shapes and volumes, the photoacoustic amplitude signal is different for each colony and species. In order to compare the samples, the area of the spectra between 400 and $4000 \mathrm{~cm}^{-1}$ was determined for each sample. The spectra were then normalized by the same constant so that they would have the same area, allowing for comparative analysis.

\section{Statistical analysis}

To quantify the differences between cuticular hydrocarbon concentration among the ant species and colonies, canonical discriminant analysis of the peak intensity in the spectra was carried out. Colonies/species were used as the factor, and the peak intensities were used as response variables. A stepwise procedure was utilized to obtain a minimum model predicting colony and species differentiation. This method was used to find the linear combinations of variables that maximize the probability of correctly assigning observations to their predetermined groups (Quinn and Keough, 2002).

\section{RESULTS AND DISCUSSION}

The average photoacoustic spectra in the mid-infrared region obtained for E. brunneum and E. vizottoi can be seen in Figure 1. There was close similarity between the spectra, indicating a need for statistical interpretation to differentiate colonies and species of ants. We compared the photoacoustic signal intensity of peaks 1 to 13 in the E. brunneum (colony 1) spectrum. These peaks can be noted in all spectra. They are related to the stretching and bending vibration mode of $\mathrm{CH}_{2}$ and $\mathrm{CH}_{3}$ of the cuticular hydrocarbon, as indicated in Table 1 (Smith, 1999). The intense peaks at 1650 and $1530 \mathrm{~cm}^{-1}$ are related to $-\mathrm{C}=\mathrm{O}$ stretching 
and $-\mathrm{N}-\mathrm{H}$ bending of secondary amides, respectively. In this region, the water vapor in the room can also absorb mid-infrared radiation and contribute to the absorption spectrum of the samples. In order to avoid any error in the statistical analysis, they were not selected. In the same way, the peak centered at $3290 \mathrm{~cm}^{-1}$ of $-\mathrm{N}-\mathrm{H}$ stretching was not used, because there is strong and broad absorption of the room air $\mathrm{OH}$ in this region. There were differences in the relationship between the intensities $\mathrm{I}_{1}$ and $\mathrm{I}_{2}$ of peaks 1 and 2 (2931 and $\left.2962 \mathrm{~cm}^{-1}\right)$; for $E$. vizottoi the $\mathrm{I}_{1} / \mathrm{I}_{2}$ relationship was greater than 1 , whereas for $E$. brunneum $\mathrm{I}_{1} / \mathrm{I}_{2}$ it was less than 1 (Figure 1). This was observed for both colonies, and suggests that these vibration modes can be used as a reference for characterizing these species of ants.

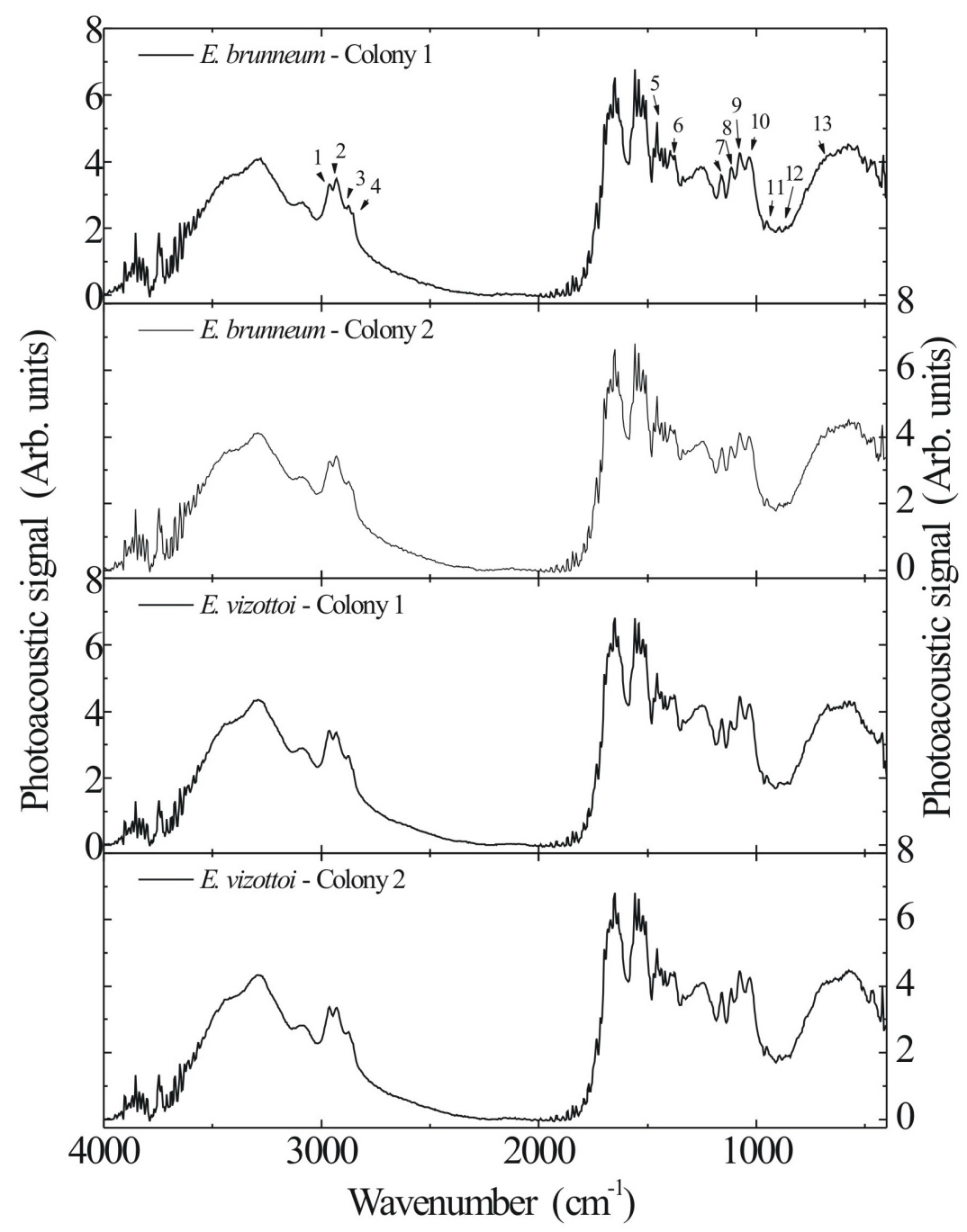

Figure 1. Average mid-infrared photoacoustic spectra obtained from the hydrocarbons of worker abdomens from two colonies of Ectatomma brunneum and two colonies of E. vizottoi. 


\begin{tabular}{|c|c|c|c|}
\hline Peak & Wavenumber $\left(\mathrm{cm}^{-1}\right)$ & Functional group & Vibration mode \\
\hline 1 & 2962 & $-\mathrm{C}-\mathrm{H}\left(\mathrm{CH}_{3}\right)$ & Asymmetric stretching \\
\hline 2 & 2931 & $-\mathrm{C}-\mathrm{H}\left(\mathrm{CH}_{2}\right)$ & Asymmetric stretching \\
\hline 3 & 2874 & $-\mathrm{C}-\mathrm{H}\left(\mathrm{CH}_{3}\right)$ & Symmetric stretching \\
\hline 4 & 2854 & $-\mathrm{C}-\mathrm{H}\left(\mathrm{CH}_{2}\right)$ & Symmetric stretching \\
\hline 5 & 1458 & $\begin{array}{l}\mathrm{C}-\mathrm{CH}_{3} \\
\mathrm{C}-\mathrm{CH}_{2}\end{array}$ & $\begin{array}{l}\text { Asymmetric bending } \\
\text { Scissors }\end{array}$ \\
\hline 6 & 1377 & $\mathrm{C}-\mathrm{CH}_{3}$ & Symmetric bending \\
\hline 7 & 1157 & & \\
\hline 8 & 1107 & In-plane C-H (benzene) & Bending \\
\hline 9 & 1076 & & \\
\hline 10 & 1030 & & \\
\hline 11 & 953 & & \\
\hline 12 & 895 & Out-of-plane C-H (benzene) & Bending \\
\hline 13 & 667 & & \\
\hline
\end{tabular}

Figure 2 illustrates the first two canonical roots revealed by canonical discriminant function analysis (Wilk's lambda $=0.032 ; \mathrm{F}_{27,82}=6.907 ; \mathrm{P}<0.001$ ) for the samples. There was a clear differentiation between ant species, principally by the first canonical root, which explained $87.8 \%$ of the data variation. The second canonical root explained $10.5 \%$, with $E$. brunneum colonies more separated than colonies of $E$. vizottoi; differences between the colonies were not significant for $E$. vizottoi. However, colonies of this species collected in very close nests could be closely related (Vieira et al., 2007).

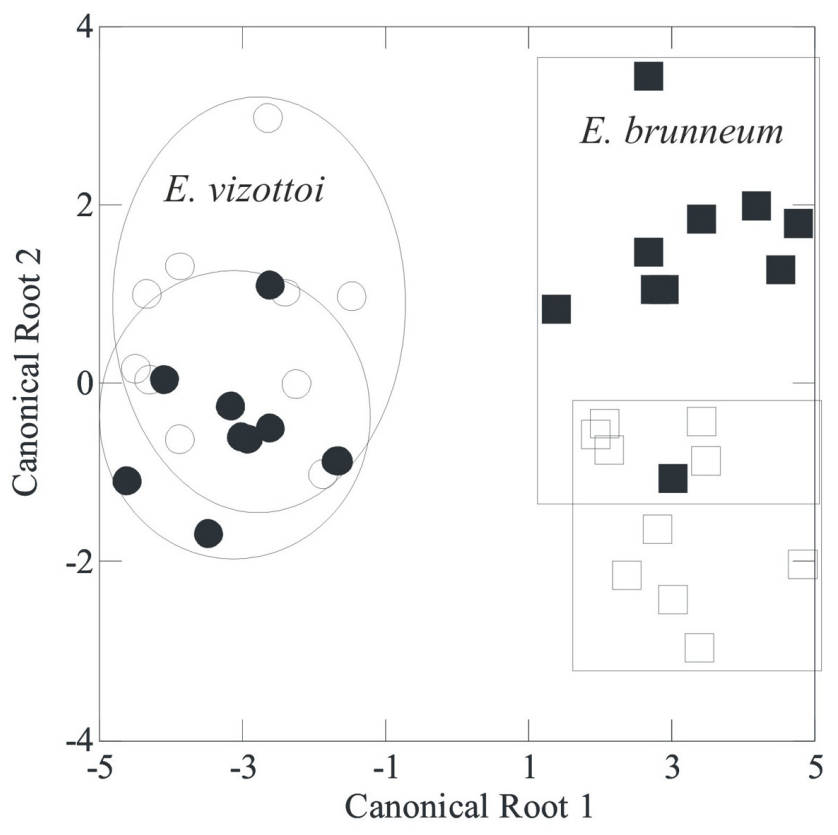

Figure 2. Scatterplot of stepwise discriminant function analysis of Fourier transform infrared photoacoustic spectroscopy peaks of the hydrocarbons of workers from colonies of Ectatomma vizottoi and E. brunneum. 
Intracolony cuticular hydrocarbons are exchanged between nestmates through trophallaxis, mutual licking and passive contact (Soroker et al., 1994, 1995; Vienne et al., 1995). These exchanges create a chemical signature (Crozier and Dix, 1979), which constitutes the reference odor used for acceptance or rejection of other individuals. In fact, the intracolony variation of cuticular hydrocarbon profiles is usually smaller than intercolony variation. Many researchers have suggested that cuticular hydrocarbon profile is most likely adopted as a 'common colony odor' for nestmate recognition (Blum, 1987; Bonavita-Cougourdan et al., 1987; Clément et al., 1987; Akino and Yamaoka, 1998). Liu et al. (2003) compared cuticular hydrocarbon profiles between workers of the ant Polyergus samurai and its slave, Formica japonica, concluding that interspecific variation was more important than intra-mixed colony variation.

The most important useful peaks for discrimination of Ectatomma species were 2962 and $2931 \mathrm{~cm}^{-1}$, for the first two canonical roots. These peaks are the same as discussed above (Figure 1). The values of the average intensity of peaks 1 and 2 were determined, and the calculated $\mathrm{I}_{1} / \mathrm{I}_{2}$ ratios were 1.012 and 0.953 for E. vizottoi and E. brunneum, respectively. The $\mathrm{I}_{1} / \mathrm{I}_{2}\left(\mathrm{CH}_{3} / \mathrm{CH}_{2}\right)$ ratio can indicate the concentration of alkane molecules with straight chains compared with branched ones. This is reinforced by the assumption that the concentration of $\mathrm{CH}_{3}$ is higher in straight than in branched alkanes (Smith, 1999). Therefore, E. brunneum has straighter alkane molecule chains than does E. vizottoi. However, in agreement with Jones et al. (2002), among the cuticular hydrocarbons, alkenes and methyl branched alkanes are probably more informative than linear alkanes for insect communication, because the latter lack stereochemical and structural features that normally trigger chemoreceptors.

For variables in the first canonical root, E. brunneum had higher peak intensities at $667,1076,2854$, and $2931 \mathrm{~cm}^{-1}$, whereas E. vizottoi had higher intensities for peaks at 1029 , $1157,1457,2873$, and $2962 \mathrm{~cm}^{-1}$. These peaks were also found to be important for discriminating castes of these species, using the same technique (Antonialli Jr. et al., 2007).

\section{CONCLUSIONS}

We found differences in cuticular hydrocarbon composition between the ants E. vizottoi and E. brunneum; this functions as a chemical signature for these species. In particular, the relationship between the $\mathrm{CH}_{3}$ and $\mathrm{CH}_{2}$ asymmetric stretching peak intensities is useful for distinguishing these ant species. The intracolony variation of cuticular hydrocarbon profiles was smaller than the intercolony variation, confirming that this methodology (FTIR-PAS combined with statistical analysis) is precise in differentiating species and can contribute to studies of social insects.

\section{ACKNOWLEDGMENTS}

The authors are grateful to UEMS, Fundect-MS, CNPq, and FINEP.

\section{REFERENCES}

Abdalla FC, Jones GR, Morgan ED and da Cruz-Landim C (2003). Comparative study of the cuticular hydrocarbon composition of Melipona bicolor Lepeletier, 1836 (Hymenoptera, Meliponini) workers and queens. Genet. Mol. Res. 2: 191-199. Akino T and Yamaoka R(1998). Chemical mimicry in the root aphid parasitoid Paralipsis eikoae Yasumatsu (Hymenoptera: Aphidiidae) of the aphid-attending ant Lasius sakagamii Yamauchi and Hayashida (Hymenoptera: Formicidae). Chemoecology 8: 153-161. 
Antonialli WF Jr, Lima SM, Andrade LH and Suarez YR (2007). Comparative study of the cuticular hydrocarbon in queens, workers and males of Ectatomma vizottoi (Hymenoptera, Formicidae) by Fourier transform-infrared photoacoustic spectroscopy. Genet. Mol. Res. 6: 492-499.

Armold MT and Regnier FE (1975). Stimulation of hydrocarbon biosynthesis by ecdysone in the flesh fly, Sarcophaga bullat. J. Insect Physiol. 21: 1581-1586.

Belton PS, Safar AM and Wilson RH (1988). The potential of Fourier transform infrared spectroscopy for the analysis of confectionery products. Food Chem. 28: 53-61.

Blomquist GJ, Tillman JA, Mpuru S and Seybold SJ (1998). The cuticle and cuticular hydrocarbons of insects: Structure, function, and biochemistry. In: Pheromone communication in social insects (Vander Meer RK, Breed M, Winston M and Espelie C, eds.). Westview Press, Boulder, 34-54.

Blum MS (1987). The bases and evolutionary significance of recognitive olfactory acuity in insect societies. In: From individual to collective behavior in social insects (Experientia Suppl. 54) (Pasteels JM and Deneuborg JL, eds.). Birkhäuser Verlag, Basel, 277-293.

Bonavita-Cougourdan A, Clément JL and Lange C (1987). Nestmate recognition: the role of cuticular hydrocarbons in the ant Camponotus vagus Scop. J. Entomol. Sci. 22: 1-10.

Carlson DA and Service MW (1979). Differentiation between species of the Anopheles gambiae Giles complex (Diptera: Culicidae) by analysis of cuticular hydrocarbons. Ann. Trop. Med. Parasitol. 73: 589-592.

Carlson DA and Milstrey SK (1990). Alkanes of four related moth species, Helicoverpa and Heliothis. Arch. Insect Biochem. Physiol. 16: 165-175.

Clément JL, Bonavita-Cougourdan A and Lange C (1987). Nestmate recognition and cuticular hydrocarbons in Camponotus vagus Scop. In: Proceedings of the Tenth International Congress of the International Union for the Study of Social Insects, Munich, 473-474.

Cobb M and Jallon JM (1990). Pheromones, mate recognition and courtship stimulation in the Drosophila melanogaster species sub-group. Anim. Behav. 39: 1058-1067.

Crozier RH and Dix MW (1979). Analysis of two genetic models for the innate components of colony odor in social Hymenoptera. Behav. Ecol. Sociobiol. 4: 217-224.

Cuvillier-Hot VV, Cobb M, Malosse C and Peeters C (2001). Sex, age and ovarian activity affect cuticular hydrocarbons in Diacamma ceylonense, a queenless ant. J. Insect Physiol. 47: 485-493.

Dietemann V, Peeters C, Liebig J, Thivet V, et al. (2003). Cuticular hydrocarbons mediate discrimination of reproductives and nonreproductives in the ant Myrmecia gulosa. Proc. Natl. Acad. Sci. U. S. A. 100: 10341-10346.

Espelie KE, Wenzel JW and Chang G (1990). Surface lipids of social wasp Polistes metricus Say and its nest and nest pedicel and their relation to nestmate recognition. J. Chem. Ecol. 16: 2229-2241.

Golden KL, Meinke JJ and Stanley-Samuelson DW (1992). Cuticular hydrocarbon discrimination of Diabrotica (Coleoptera: Chrysomelidae) sibling species. Ann. Entomol. Soc. Am. 85: 561-570.

Haverty MI, Page M, Nelson LJ and Blomquist GJ (1988). Cuticular hydrocarbons of the dampwood termites, Zootermopsis: Intra- and intercolony variation and potential as taxonomic characters. J. Chem. Ecol. 14: 1035-1058.

Jones G, Beard R, Dani F and Turrilazzi S (2002). The physical and chemical properties of insect cuticular hydrocarbons. Proceedings of the XIV International Congress of the IUSSI. International Union for the Study of Social Insects (IUSSI), Sapporo, 11.

Kaib M, Brandl R and Bagine RKN (1991). Cuticular hydrocarbons among the eight species of the Drosophila melanogaster sub-group. Evolution 41: 249-302.

Lavine BK and Carlson DA (1991). Taxonomy based on chemical constitution: differentiation of New World from Old World Helicoverpa moths. Microchem. J. 43: 35-41.

Lenoir A, Fresneau D, Errard C and Hefetz A (1999). The individuality and the colonial identity in ants: the emergence of the social representation concept. In: Information processing in social insects (Detrain C, Deneubourg JL and Pasteels J, eds.). Birkhäuser, Basel, 219-237.

Letzelter NS, Wilson RH, Jones AD and Sinnaeve G (1995). Quantitative determination of the composition of individual pea seeds by Fourier transform infrared photoacoustic spectroscopy. J. Sci. Food Agric. 67: 239-245.

Liebig J, Peeters C, Oldham NJ, Markstadter C, et al. (2000). Are variations in cuticular hydrocarbons of queens and workers a reliable signal of fertility in the ant Harpegnathos saltator? Proc. Natl. Acad. Sci. U. S. A. 97: 4124-4131.

Liu Z, Bagnères AG, Yamane S, Wang Q, et al. (2003). Cuticular hydrocarbons in workers of the slave-making ant Polyergus samurai and its slave, Formica japonica (Hymenoptera: Formicidae). Entomol. Sci. 6: 125-133.

Lockey KH (1991). Insect hydrocarbon classes: Implications for chemotaxonomy. Insect Biochem. 21: 91-97.

Peeters C, Monnin T and Marlosse C (1999). Cuticular hydrocarbons correlated with reproductive status in a queenless ant. Proc. R. Soc. Lond. B. 266: 1323-1327. 
Pennanec'h M, Pho DB, Pechine JM and Jallon JM (1995). Insect hydrocarbons: analysis, structures and functions. EPPO Bull. 25: 343-348.

Phillips A, Milligan PJ, Maroli M, Lane RP, et al. (1990). Intraspecific variation in the cuticular hydrocarbons of the sandfly Phlebotomus perfiliewi from Italy. Med. Vet. Entomol. 4: 451-457.

Quinn GP and Keough MJ (2002). Experimental design and data analysis for biologists. Cambridge University Press, Cambridge.

Raboudi F, Mezghani M, Makni H, Marrakchi M, et al. (2005). Aphid species identification using cuticular hydrocarbons and cytochrome $b$ gene sequences. J. Appl. Entomol. 12: 75-80.

Rosencwaig A (1980). Photoacoustic and photoacoustic spectroscopy. Wiley Interscience, New York.

Seifert B (1991). Lasius platythorax n. sp, a widespread sibling species of Lasius niger (Hymenoptera, Formicidae). Entomol. Gen. 16: 69-81.

Smith B (1999). Infrared spectral interpretation, a systematic approach. CRC Press, Boca Raton.

Soroker V, Vienne C, Hefetz A and Nowbahari E (1994). The postpharyngeal gland as a "Gestalt" organ for nestmate recognition in the ant Cataglyphis niger. Naturwissen 81: 510-513.

Soroker V, Vienne C and Hefetz A (1995). Hydrocarbon dynamics within and between nestmates in Cataglyphis niger (hymenoptera: formicidae). J. Chem. Ecol. 21: 365-378.

Takematsu Y and Yamaoka R (1999). Cuticular hydrocarbons of Reticulitermes (Isoptera: Rhinotermitidae) in Japan and neighboring countries as chemotaxonomic characters. Appl. Entomol. Zool. 34: 179-188.

Vieira AS, Antonialli WF Jr and Desidério W (2007). Modelo arquitetônico de ninhos da formiga Ectatomma vizottoi Almeida, 1987. Rev. Bras. Entomol. 51: 313-317.

Vienne C, Soroker V and Hefetz A (1995). Congruency of hydrocarbon patterns in heterospecific groups of ants: transfer and/or biosynthesis? Insectes Soc. 42: 267-277. 